
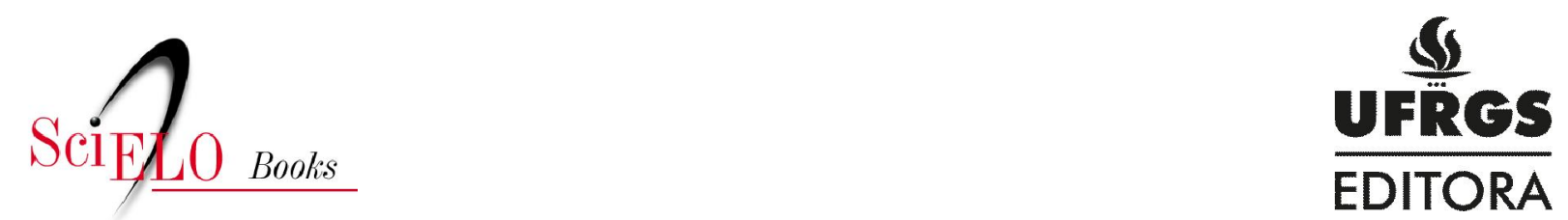

\title{
Riscos macrofinanceiros, preferência pela liquidez e acumulação real no capitalismo financeirizado
}

\author{
Marcelo Milan
}

\section{SciELO Books / SciELO Livros / SciELO Libros}

MILAN, M. Riscos macrofinanceiros, preferência pela liquidez e acumulação real no capitalismo financeirizado. In: DATHEIN, R., org. Desenvolvimentismo: o conceito, as bases teóricas e as políticas [online]. Porto Alegre: Editora da UFRGS, 2003. Estudos e pesquisas IEPE series, pp. 311344. ISBN 978-85-386-0382-5. Available from doi: 10.7476/9788538603825. Also available in ePUB from: http://books.scielo.org/id/8m95t/epub/dathein-9788538603825.epub.

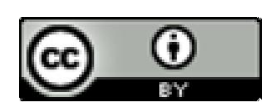

All the contents of this work, except where otherwise noted, is licensed under a Creative Commons Attribution 4.0 International license.

Todo o conteúdo deste trabalho, exceto quando houver ressalva, é publicado sob a licença Creative Commons Atribição $\underline{4.0}$.

Todo el contenido de esta obra, excepto donde se indique lo contrario, está bajo licencia de la licencia Creative Commons $\underline{\text { Reconocimento } 4.0 .}$. 


\section{Riscos macrofinanceiros, preferência pela liquidez e acumulação real no capitalismo financeirizado}

Marcelo Milan

\section{Introdução}

O aumento da volatilidade e da instabilidade nos mercados financeiros se tornou uma característica importante da economia mundial desde os anos 1970, com preços e fluxos financeiros, em geral, e taxas de juros e taxas de câmbio, em particular, experimentando variações substanciais em qualquer lapso de tempo que se considere. Essas flutuações, assim como as crises que caracterizam as últimas décadas, refletem uma modificação significativa na orientação da política financeira nos países capitalistas avançados, com o abandono dos controles macrofinanceiros e a crescente adoção da liberalização e desregulamentação financeira, que foi logo em seguida exportada aos demais países (Cargill, 1997). ${ }^{1}$ Ou seja, o neoliberalismo altera a maneira como a instabilidade econômica em geral e a volatilidade financeira em particular são tratadas no plano político-institucional. Subjacente a esta mudança se encontra a rápida transformação dos mercados financeiros na década de 1960 e início de 1970, com a introdução de uma série de inovações financeiras que conduziram a uma explosão de ativos e passivos financeiros. O desdobramento e a convergência dessas duas tendências desencadearam a mudança estrutural conhecida como "financeirização".

${ }^{1}$ Com a exceção da economia chilena, pioneira na aplicação dos experimentos neoliberais propostos originalmente pela sociedade Mont Pelerin. 
Esse fenômeno pode ser definido de várias maneiras. Uma definição a concebe como a crescente aquisição, por parte das empresas não financeiras, de ativos financeiros e subsidiárias financeiras para aumentar receitas e lucros, implicando uma redução relativa nos negócios tradicionais de produção e comércio. A financeirização pode alternativamente ser entendida como a crescente importância assumida por instituições e mercados financeiros na determinação dos ritmos de acumulação de capital, da produção e distribuição da renda e riqueza, e na ampliação da instabilidade e geração contínua de crises (Stockhammer, 2004; Epstein, 2005; Krippner, 2005; Orhangazi, 2008).

Dentro dessa segunda definição, que será o objeto deste capítulo, ênfase deve ser dada ao rápido crescimento dos derivativos financeiros, introduzidos nas décadas de 1970 e $1980 .^{2}$ Segundo o Banco de Compensações Internacionais (BIS), considerando apenas as transações de balcão, as mesmas atingiram um montante global nocional de cerca de US\$ 615 trilhões em dezembro de 2009, após um pico de US\$ 684 trilhões durante o primeiro semestre de 2008, contra US\$ 72 trilhões ao final de 1998. O valor bruto de mercado - o custo de substituição de todos os contratos em aberto, e certamente uma medida mais precisa dos valores transacionados - passou de US\$2,6 trilhões para US\$ 21,6 trilhões no mesmo período, após o pico de US\$32,4 trilhões em dezembro de 2008 (BIS, 2010). Essa rápida expansão dos derivativos financeiros sintetiza as transformações acima mencionadas, que convergem para a formação de um capitalismo financeirizado. Por um lado,

\footnotetext{
${ }^{2}$ Existem diferentes classificações para os contratos que envolvem de forma agregada os diferentes tipos de contratos futuros, forwards, opções e swaps, dependendo do ativo ou transação que origina sua criação (Hull, 1995). As classificações incluem derivativos de mercadorias do Setor Primário, derivativos financeiros e derivativos de crédito. Além disso, derivativos mais complexos são normalmente criados por uma combinação dos instrumentos mencionados anteriormente. Este capítulo aborda apenas os tipos simples de derivativos financeiros relacionados à proteção privada contra os riscos macrofinanceiros, isto é, riscos associados a variações na taxa de juro e na de taxa de câmbio, e não com instrumentos complexos ou mesmo derivativos financeiros utilizados para supostamente alinhar a remuneração dos executivos com o desempenho corporativo no caso das sociedades anônimas. Também não se considera o emprego de swaps de moedas pelos bancos centrais como mecanismo potencialmente estabilizador do câmbio. Finalmente, não se consideram outras funções dos derivativos discutidas na literatura, como, por exemplo, a descoberta de preços nos mercados dos ativos originários ou melhor acesso a financiamento.
} 
as inovações financeiras e a reorientação da política financeira, no sentido de maior liberalização e desregulamentação dos mercados financeiros contribuiu para modificar os mecanismos de criação de riscos macrofinanceiros, ampliando a volatilidade. Por outro, essas mudanças levaram à adoção de uma abordagem privatizante para a gestão desses riscos financeiros amplificados no processo, em que os derivativos potencialmente ofertam instrumentos para mitigar esses riscos elevados. Assim, a expansão dos derivativos tem contribuído enormemente para a crescente importância das instituições e dos mercados financeiros na atual fase do capitalismo financeirizado, tanto como fonte de lucros como fonte de perdas que amplificam a instabilidade financeira, como exemplificado pela crise global de 2007.

O objetivo deste capítulo é duplo. Em primeiro lugar, procura-se entender a financeirização por meio da transformação da formação e do tratamento dos riscos macrofinanceiros. Tenta-se adicionalmente entender as consequências dessas mudanças para a acumulação de ativos e para o crescimento econômico. Para atingir esses objetivos, o estudo compara, em termos históricos, o regime de regulamentação e controles com a abordagem da gestão privada dos riscos macrofinanceiros por meio de derivativos financeiros, e deriva teoricamente possíveis consequências em termos da composição de ativos das empresas. A acumulação de ativos reais está intrinsecamente relacionada ao crescimento e, à medida que afeta a distribuição de renda e o meio-ambiente, ao desenvolvimento. A variável privilegiada para efetuar a comparação institucional e derivar consequências para a acumulação de capital é a preferência pela liquidez, o mecanismo padrão de proteção em uma economia capitalista atormentada pela incerteza fundamental. A fuga dos ativos ilíquidos reduz a acumulação de capital e o crescimento. E mesmo uma maior acumulação financeira não conduz necessariamente à acumulação de capital, já que pode simplesmente ampliar a circulação de fundos na esfera financeira, reforçando a financeirização.

Ou seja, o trabalho procura entender como as instituições e as inovações, a regulamentação e os derivativos podem afetar a liquidez dos diferentes ativos, principalmente por meio de mudanças nos mecanismos pelos quais as fontes de incerteza, como os riscos macrofinanceiros, são criados e controlados. Isto é, o desenvolvimento de formas alternativas de contenção da volatilidade financeira e seus efeitos pode modificar a 
participação dos ativos líquidos utilizados como cobertura contra riscos. E a preferência pela liquidez pode ter sido afetada pelo fim do sistema de regulamentação e controles e pelo desenvolvimento dos derivativos para tratar da volatilidade financeira. Um dos argumentos centrais deste trabalho postula que a rápida expansão dos derivativos não pode ser assumida a priori como o resultado direto de sua eficácia superior em comparação com outras ferramentas administrativas de controle de riscos, como querem os economistas ortodoxos. Outras explicações devem ser consideradas na compreensão do crescimento e das funções desempenhadas pelos derivativos financeiros no comportamento dos preços e fluxos macrofinanceiros em comparação com a abordagem dos controles administrativos, sendo a financeirização uma forte candidata.

O capítulo está organizado da seguinte maneira: após esta introdução, a seção 2 discute a evolução institucional do tratamento dos riscos macrofinanceiros e o movimento no sentido da financeirização. Em seguida, a literatura sobre a preferência pela liquidez em condições de risco ou incerteza é tratada, enfatizando em particular como diferentes formas de tratar os riscos macrofinanceiros podem afetar a preferência pela liquidez das empresas.

\section{A evolução histórica do tratamento dos riscos macrofinanceiros}

Peter Bernstein (1998) observa que a atividade de assumir riscos envolve distintos graus de conhecimento sobre os resultados futuros e sugere que a gestão de riscos se caracteriza pela maximização das áreas em que existe um maior controle sobre os resultados e pela minimização daquelas em que não há qualquer controle, por falta de conhecimento das relações de causa e de efeito. Obviamente, essa ignorância é intrínseca às decisões de investimento e produção sob o capitalismo, como enfatizado por Keynes. Poderia ser argumentado adicionalmente que aquelas áreas de segurança reduzida, ou talvez de ignorância completa, não são fixas, e as mudanças econômicas e os diferentes arranjos institucionais podem aumentá-las ou diminuí-las, ou mesmo transformar as relações econômicas e financeiras de tal forma que torne o conhecimento existente sobre relações específicas entre causa e efeito irrelevante. 
Nesse sentido, Minsky (1979) mostra como posições financeiras individuais sólidas, isto é, com áreas de controle supostamente maiores, possivelmente consideradas sob controle, podem ser indicadores enganosos quando os incentivos de lucro e a dinâmica de todo o sistema financeiro são consideradas. A possibilidade de mudanças rápidas, que faz com que as posições consideradas menos arriscadas se tornem mais frágeis e desestabilizadoras, sugere que os comportamentos inicialmente compatíveis com a maximização do conhecimento e minimização da incerteza são igualmente propícios a resultados inesperados e comportamentos desestabilizadores e que estes reduzem o nível de controle sobre os resultados quando a crise eclode. Ou seja, balanços patrimoniais interligados podem levar a uma cadeia de eventos em que posições financeiras individuais levam à fragilidade financeira sistêmica, aumentando as áreas opacas anteriormente assumidas como estando sob algum controle ao nível da empresa. Isto é, não há coerência micro e macroeconômica no capitalismo realmente existente. Da mesma forma, poder-se-ia assumir que uma maior volatilidade financeira tende a intensificar a incerteza e aumentar as áreas incontroláveis, uma vez que o grau de imprevisibilidade sobre futuros parâmetros financeiros e projeções de fluxo de caixa é ampliado nessa situação.

Dado que a incerteza fundamental causada por flutuações imprevisíveis nos preços e quantidades e pela variação correspondente nas rendas, é inerente ao capitalismo, o objetivo de qualquer mecanismo econômico ou político de gestão de riscos financeiros é justamente evitar a volatilidade ou atenuar os seus efeitos, aumentando o grau de controle sobre os resultados. A experiência financeira recente do capitalismo global aponta para a existência de distintos mecanismos, instituições e arranjos político-econômicos de gestão de riscos macrofinanceiros. Esses mecanismos podem transformar parte da incerteza global, intrínseca em processos descentralizados sem coordenação a priori, típicos de uma economia capitalista desregulada, em alguma forma de risco controlável. Podem também, é claro, exacerbá-la. Assim, a eficácia de cada mecanismo institucional pode ser avaliada em termos de sua capacidade de mitigar os riscos macrofinanceiros ou, pelo menos, os efeitos negativos desses riscos sobre as decisões econômicas e financeiras. Mas essa avaliação exige um entendimento prévio de como esses diferentes mecanismos conseguiram ou não controlar os riscos macrofinanceiros. 
A introdução dos derivativos financeiros nos EUA, em 1972, representou um divisor de águas na história dos mercados financeiros. Esses instrumentos representam um elemento fundamental na transição de um regime de regulação e controle financeiros para um regime em que o gerenciamento dos riscos, criados livremente, é privatizado. Nesse caso, os riscos financeiros são assumidos como dados, e então precificados e negociados no mercado de derivativos. Por outro lado, até o momento em que Richard Nixon decidiu cancelar a convertibilidade do dólar em ouro, em 1971, e posteriormente quando as inovações financeiras que reduziam a eficácia dos controles foram consolidadas pelas reformas bancárias e financeiras de Reagan, Bush e Clinton. nos anos 1980 e 1990, dois dos mais importantes riscos macrofinanceiros, as taxas de juros e de câmbio, ${ }^{3}$ eram geridas através de uma variedade de mecanismos administrativos por meio de coordenação internacional e de controles e regulamentações nacionais, discutidos a seguir.

\subsection{Os controles internacionais e domésticos da volatilidade financeira}

Apesar de ser um arranjo multifacetado que compreende diversas características institucionais, o acordo de Bretton Woods teve duas características particularmente importantes para o controle dos riscos macrofinanceiros. O sistema foi ancorado em um sistema de taxas fixas mas ajustáveis de câmbio e em controles dos fluxos de capitais. Tais medidas

\footnotetext{
${ }^{3}$ Os preços macrofinanceiros mais importantes para o financiamento da acumulação de capital por meio de obrigações são as taxas de juros e taxas de câmbio, e não as ações. Apesar de as quebras bursáteis terem impactos macroeconômicos, o preço das ações e sua volatilidade no mercado secundário estão vinculados à esfera da gestão da riqueza privada, já que são títulos transferíveis de propriedade restritos a uma pequena parcela da sociedade, e não diretamente às estratégias corporativas de financiamento de ativos (Froot et al., 1994). Além disso, a volatilidade que ocorre no mercado primário é absorvida pelos bancos responsáveis pela subscrição e lançamento das ações. Por sua vez, as operações de crédito e emissão de títulos são mais difundidas para financiar investimentos, e a mundialização tornou a taxa de câmbio uma variável-chave nas operações das empresas. Justifica-se assim a ausência de regulamentação rigorosa e explícita da volatilidade do preço das ações. Da mesma forma, o fato de a maior parte das transações envolvendo derivativos financeiros, com a possível exceção das opções, serem baseadas em taxas de juros ou câmbio, corrobora a ênfase nesses preços macrofinanceiros.
} 
impuseram limites ao papel dos mercados financeiros na determinação exclusiva do preço das divisas internacionais e, por conseguinte, na criação de volatilidade. Apesar de os EUA não adotarem tais controles até 1963, com a introdução do imposto para a equalização das taxas de juros (Neely, 1999), o governo estadunidense apoiou a adoção de tais controles por outros países, reforçando a sua eficácia no combate aos ajustes, potencialmente desestabilizadores, de carteira entre os países (Helleiner, 1994). É importante notar que essas duas características se complementavam com as taxas nominais fixas de câmbio impedindo uma volatilidade excessiva nos preços, e com os controles evitando o papel potencialmente desestabilizador dos fluxos livres de capitais internacionais.

Assim, em vez de completa liberdade de compra e venda de moeda estrangeira, as taxas de câmbio foram determinadas por arranjos políticos e de negociação cooperativa, com as instituições de governança estatal se sobrepondo às instituições e aos mercados financeiros. Apesar de possíveis divergências políticas sobre o fato de as paridades terem sido determinadas de forma ad hoc, a fixação do câmbio não se deu de forma mais errática do que preços determinados por mercados financeiros caracterizados por excessos especulativos desestabilizadores. E o sistema de taxas fixas mas ajustáveis reduziu de forma quase absoluta a volatilidade cambial nominal, possivelmente contribuindo para taxas elevadas de crescimento econômico, já que os preços domésticos mais estáveis contribuíram para não exacerbar a volatilidade real.

Essas duas características de Bretton Woods constituem o primeiro componente de um regime de controles administrativos. Ao nível doméstico, isolada dos fluxos potencialmente desestabilizadores de capitais internacionais de curto prazo, a política monetária poderia se voltar a promover o pleno emprego através de taxas de juros reduzidas, e algumas políticas nacionais também tinham como meta manter as taxas de juros estáveis, além de controles quantitativos sobre a intermediação financeira. Dessa forma, duas características do quadro regulatório estadunidense podem ser pensadas como estando em conformidade com um segundo componente do conjunto de medidas de regulamentação e controles financeiros. Nos EUA a regulamentação Q impôs controles sobre as taxas que os bancos poderiam pagar aos depósitos à vista e a prazo (Russell, 2008; Hubbard, 1999). Tais medidas impuseram limites superiores à flutuação das taxas nominais de juros, que acabaram por inibir grandes flutuações nas demais taxas de juros e no preço dos títulos emitidos por empresas e governos. 
Ao mesmo tempo, a regulamentação Glass-Steagall, ao separar os bancos comerciais dos bancos de investimento, criou as condições necessárias para reduzir flutuações excessivas das taxas de juros. Isso foi feito por meio da influência da política monetária sobre o fluxo dos recursos intermediados pelos bancos comerciais, com o objetivo explícito de impedir a utilização especulativa de parte considerável da oferta de moeda doméstica (Russell, 2008). ${ }^{4}$ Como uma parcela considerável dos fundos de curto prazo é intermediada através do sistema bancário comercial, o controle das reservas dos bancos por meio de operações de mercado aberto criou um importante mecanismo de administração da direção dos fluxos de fundos, além de estabilizar as taxas de juros de curto prazo. Portanto, assim como os controles de capitais desempenharam um papel importante na manutenção das paridades cambiais, a segregação dos bancos forneceu ferramentas complementares para o Estado controlar os riscos macrofinanceiros. Além disso, os mercados de crédito e de câmbio estão conectados por diversos canais, e as medidas reforçaram a estabilidade financeira sistêmica.

Assim, tanto a coordenação internacional dos controles de capital e das paridades cambiais quanto à regulamentação financeira doméstica e os controles das taxas de juros e fluxos de fundos podem ser pensados como componentes de um mecanismo administrativo de gestão dos riscos macrofinanceiros. Cargill (1997) resume de forma precisa o papel dos controles administrativos e a rejeição de uma abordagem liberal aos riscos financeiros nos Estados Unidos. Segundo o autor, os mercados financeiros eram considerados intrinsecamente instáveis, e para controlá-los foram adotados o câmbio fixo, restrições ao ajuste das carteiras de ativos financeiros e limites às taxas domésticas de juros.

Uma rápida avaliação desse regime sugere que, por cerca de um quarto de século, os controles foram bem sucedidos em reduzir a volatilidade causada por grandes fluxos financeiros desestabilizadores e em amortecer a volatilidade excessiva nos preços financeiros. Se a interpretação é correta, pode-se afirmar que esse regime regulatório se constituiu em um ingrediente integral na formação de uma Idade de Ouro do capitalismo,

\footnotetext{
${ }^{4}$ Isso implicitamente requer que posições especulativas não sejam financiadas endogenamente pelo sistema financeiro, por meio de inovações que contornariam as limitações impostas pela existência da separação, o que aparentemente não ocorreu no período considerado.
} 
permitindo mesmo a industrialização de alguns países periféricos. As sinergias existentes entre a regulação financeira e as políticas econômicas internas voltadas ao pleno emprego e ao controle cíclico do produto não podem ser subestimadas. Minsky (1975) observa que a teoria keynesiana das flutuações no investimento associadas à instabilidade da demanda é, em primeiro lugar, uma teoria financeira, sugerindo que os controles financeiros, à medida que são efetivos, podem ter importantes consequências macroeconômicas. E a dimensão central dos riscos macrofinanceiros no controle das diversas fontes de incerteza deste programa de estabilização se torna mais clara quando se percebe que um dos principais componentes, senão o principal, da contrarrevolução neoliberal foram justamente os controles financeiros.

Crotty (2005) argumenta que, sob o neoliberalismo, a desregulamentação e liberalização dos mercados financeiros, e poder-se-ia acrescentar a deliberada falta de coordenação e articulação entre as políticas embutidas na doutrina do livre cambismo, contribuíram enormemente para agravar todas as formas diferentes de incerteza e riscos característicos da competição destrutiva. O ex-presidente da Reserva Federal Allan Greenspan reconhece, seguindo Keynes, que o futuro é imprevisível, e que os banqueiros centrais precisam decidir entre regulamentar os mercados e assim sufocar a inovação e o crescimento, ou liberalizá-los e desregulamentá-los e suportar as crises que se seguem, mas que não reduzem o crescimento de longo prazo (IP, 2008). Minsky (1979, p. 36. Tradução do autor) afirma que "todos os capitalismos são instáveis, mas alguns capitalismos são mais instáveis do que os outros”. A história financeira recente sugere que o capitalismo desregulado é mais instável do que o capitalismo regulado, principalmente o capitalismo regulado que controla de forma estrita os mercados financeiros, apesar dos desafios apresentados pela "dialética regulatória". ${ }^{5}$ As diferenças entre os dois tipos de capitalismo sugeridas por Greenspan e Minsky não podem ser subestimadas, e a crise financeira de 2007 deixou claro que a concepção de Greenspan estava equivocada, levando-o a rejeitar sua fé no livre-mercado (Andrews, 2008).

\footnotetext{
${ }^{5}$ Edward Kane denomina de "dialética regulatória" a contínua introdução de inovações nos mercados financeiros para contornar os regulamentos existentes. Com o enfraquecimento da regulamentação existente, uma nova regulamentação é introduzida, apertando os controles e induzindo novas inovações financeiras e assim por diante (Russell, 2008).
} 


\subsection{O aumento da volatilidade e os derivativos financeiros}

O fim do regime de regulação financeira provocou um aumento substancial na volatilidade. Com elevados riscos financeiros, um novo mecanismo foi necessário para isolar as decisões financeiras das novas condições de mercado, e os derivativos financeiros podem ter sido criados como uma resposta a essa necessidade. Se essa hipótese é aceita, então fica evidente a importância de se criarem condições para evitar a volatilidade excessiva, quer no nível da política, quer no nível privado. Isto é, o rápido crescimento dos derivativos poderia sugerir que a volatilidade é indesejável e deve ser tratada, de alguma forma, na ausência de regras e controles.

O surgimento dos derivativos financeiros é relativamente incontroverso. De acordo com Swan (2000), os derivativos são tão antigos quanto o dinheiro. Há registros de transações envolvendo contratos futuros de commodities que ocorreram cerca de 4.000 anos na Mesopotâmia. Desde então, as operações evoluíram de transações dispersas para negociações em mercados cada vez mais organizados, com instrumentos sofisticados. No entanto, na maior parte do tempo, as operações primárias envolviam apenas commodities. Nos Estados Unidos, o Conselho de Comércio de Chicago (CBOT) foi criado em 1848, e a Bolsa Mercantil de Chicago (CME), em 1874, voltados para o comércio de contratos futuros de alguns produtos agrícolas específicos (Hull, 1995). Os derivativos financeiros assumiram um papel fundamental apenas durante a década de 1970, superando, desde então, os derivativos de commodities tradicionais. O Mercado Monetário Internacional (IMM) foi formado em 1972, como uma divisão da CME, para negociar contratos futuros em moeda estrangeira. O Conselho da Bolsa de Opções de Chicago (CBOE) foi criado em 1973, como uma divisão do CBOT. Títulos lastreados em hipotecas emitidos pela Ginnie Mae, que oferece seguro contra inadimplência para empréstimos imobiliários, foram introduzidos pelo CBOT, em 1975. O primeiro contrato de swap negociado em bolsa foi emitido em 1981. O primeiro contrato futuro do índice de ações Standard \& Poor 500 foi negociado em 1982 (Hull, 1995; Bryan; Rafferty, 2006; Steinherr, 2000).

No mecanismo privatizado de gestão de riscos financeiros tendo por base os derivativos, empresas expostas a riscos financeiros, ou dispostas 
a especular, podem comprar proteção entrando em um contrato com uma outra parte disposta a assumir esses riscos. As transações financeiras privadas determinam os preços e os fluxos financeiros relevantes, e os derivativos financeiros surgem como forma de tratar a volatilidade resultante. Os derivativos financeiros protegem potencialmente contra os riscos ao fixar os parâmetros financeiros futuros ou substituir variáveis flutuantes por fixas em acordos de swaps, compensando os riscos correspondentes de flutuação no preço da variável subjacente ou nos pagamentos de juros. Esses instrumentos podem ser negociados através de acordos bilaterais, em mercados desregulamentados de balcão, com produtos personalizados, ou em bolsas organizadas, com contratos padronizados e de liquidação fornecidos através de câmaras de compensação, sendo os mercados de balcão os mais importantes em termos de volume e número de contratos negociados.

Em um contexto de volatilidade financeira criada pelo próprio funcionamento dos mercados desregulados, o preço do instrumento primário varia imprevisivelmente ao longo do tempo, e os ganhos ou perdas são conhecidos apenas no vencimento ou quando as posições são fechadas, criando riscos. Esses riscos no nível da empresa podem ser eliminados pelos derivativos, cujos preços flutuam sempre na direção contrária quando empregados para proteção, compensando uma perda em termos de ampliação dos compromissos financeiros existentes com um ganho de igual magnitude. Ou seja, com derivativos, os riscos são separados da variável primária e colocados à venda para agentes dispostos a absorver esses riscos ou ainda passá-los a terceiros através do sistema financeiro. Assim, os riscos são cobertos pela sua transferência para um portador diferente, mas não são eliminados. Nessas transações, não há transferência de propriedade ou mesmo a entrega do subjacente, com exceção de alguns mercados de forwards envolvendo câmbio, e os contratos são liquidados em dinheiro.

Uma possível interpretação para o surgimento dos derivativos está no aumento da volatilidade. Erik Banks (1994) destaca as perdas potenciais associadas às flutuações nos preços macrofinanceiros para justificar a existência de mecanismos de gerenciamento de riscos como os derivativos financeiros. Assim, os movimentos nos preços financeiros que regem muitas transações produzem riscos de perdas e sem essa volatilidade, não haveria necessidade de produtos derivativos. Merton Miller (1997), que 
trata risco e incerteza de forma indistinta, enfatiza da mesma forma que uma maior incerteza causada pela volatilidade cambial levou as instituições financeiras a inovar, introduzindo instrumentos financeiros derivativos para negociar moedas estrangeiras na Bolsa Mercantil de Chicago após o fim do sistema de Bretton Woods, bem como outros instrumentos, à medida que a volatilidade contagiou as taxas de juros. Banks (1993) igualmente destaca as conexões entre as taxas de câmbio à vista e futuras, e os diferenciais internacionais das taxas de juros, mostrando como a volatilidade ampliada em um mercado, após Bretton Woods, contagia o outro. Cargill (1997) argumenta no mesmo sentido, mostrando que o início das reformas financeiras com base na desregulamentação e liberalização coincidiu com o fim do sistema de Bretton Woods. Como os governos já não eram capazes de isolar os preços macrofinanceiros das ações das instituições financeiras, os mercados de câmbio e de crédito tornaram-se cada vez mais interligados, e as restrições de preços não poderiam ser sustentadas em apenas um conjunto de mercados, com o consequente abandono da regulação representando uma grande mudança na orientação política. Mas, como será discutida adiante, essa interpretação pode não ser totalmente correta.

\subsection{Uma avaliação: do regime de regulamentação}

e controles à gestão privatizada dos riscos macrofinanceiros

O rápido crescimento dos derivativos que se seguiu ao fim do regime de regulamentação e controles, assim como o grande número de tentativas governamentais de implementar mecanismos de estabilização cambial desde então, atestam a necessidade de gerenciar riscos financeiros e para os perigos de se aumentar a volatilidade financeira sem proteção. A mudança de orientação política na forma de tratar a volatilidade nas taxas de juros foi resumida por Albert Wojnilower (1980), que enfatiza o papel da Regulamentação Q na estabilização das taxas de juros até os anos 1960 e o abandono de qualquer tentativa de conter a volatilidade na taxa de juros por meio de intervenções no mercado de títulos a partir dos anos 1970 . Ou seja, o governo abriu mão da resposabilidade pelo fornecimento de preços e fluxos financeiros estáveis no mercado de crédito e de títulos. Richard Marston (1993) aponta as diferenças fundamentais entre as duas abordagens em termos das taxas 
de câmbio. Segundo ele, a experiência com o câmbio flexível trouxe um sentimento de nostalgia do período de taxas fixas com níveis reduzidos de risco. A volatilidade que se seguiu produziu uma situação em que posições a descoberto poderiam gerar ganhos ou perdas substanciais quando comparadas ao regime de Bretton Woods. Alfred Steinherr (2000) enfatiza a conexão entre o surgimento de derivativos financeiros e o fim da arquitetura financeira internacional erguida em torno de Bretton Woods, mas em um contexto mais amplo de inovações, como, por exemplo, o desenvolvimento do mercado de eurodólares. ${ }^{6}$

Parece equivocado assumir, como o fazem John Eatwell e Lance Taylor (2000) e Edward LiPuma e Lee Benjamin (2004), que os riscos foram privatizados durante essa transição. A ascensão histórica da gestão de riscos financeiros com base em contratos derivativos privados está associada ao fim do regime de regulação e controle de riscos, e não particularmente a um regime de socialização das perdas associadas a estes riscos, que é um traço característico do capitalismo. Os riscos de perdas são e sempre foram um encargo privado sob um sistema descentralizado de busca ao lucro, em que os preços voláteis constituem um importante parâmetro nos processos privados de tomada de decisão. No âmbito do quadro institucional neoliberal, apenas os mecanismos para lidar com elevados riscos financeiros foram privatizados. No período anterior, o Estado não assumia o risco de flutuações da taxa de juro ou de câmbio, como se houvesse alguma forma de monopólio estatal sobre o crédito interno e as divisas internacionais, ou uma socialização de perdas financeiras que a exposição ao risco do gerou para o governo. O Estado simplesmente regulava e controlava fluxos financeiros de forma de prevenir os mercados financeiros de criarem uma volatilidade excessiva aos participantes, considerando-se os potenciais benefícios macroeconômicos desses controles administrativos.

De qualquer forma, as diferenças de abordagem são profundas. A regulamentação reduz ou elimina a fonte primária dos riscos, isto é, a liberdade irrestrita de contratação nos mercados financeiros. A po-

\footnotetext{
${ }^{6}$ Miller (1997) argumenta que algumas destas respostas, principalmente os derivativos que tratam da volatilidade nos mercados de ações, já estavam sendo desenvolvidas antes do fim de Bretton Woods, mas não foram implementados - como não poderia deixar de ser - por problemas de regulamentação.
} 
lítica é efetivada ao não permitir ajustes instantâneos nas carteiras de investimentos e ao controlar os fluxos potencialmente desestabilizadores de fundos, usando tanto controles de preço quanto de quantidade. Com a privatização da gestão dos riscos, os mesmos não são reduzidos ou eliminados, o que terminaria por extinguir o mercado em que os derivativos são negociados, mas apenas compensados por meio de redistribuição para um número potencialmente maior de carteiras e entidades, diluindo, em tese, o processo de exposição aos riscos. Pode-se argumentar que o objetivo da regulação financeira é criar um ambiente mais estável no agregado que se reflete ao nível da empresa, enquanto os derivativos financeiros potencialmente executam esta função exclusivamente em nível individual, mas sem qualquer coerência ex ante com os impactos decorrentes sobre os agregados econômicos, na forma de crises financeiras, por exemplo.

Isto sugere que a regulação financeira eficaz, à medida que impede, ex ante, movimentos de substância nos preços macrofinanceiros, pode tornar os riscos de mercado insignificantes, evitando assim a necessidade de acordos privados para tratá-los ex post. Com a reversão das medidas regulatórias, os derivativos financeiros se impuseram como a forma de tratamento dos riscos financeiros. Mas é importante ressaltar que, na medida em que os derivativos podem fornecer técnicas potencialmente eficazes de cobertura de riscos financeiros, eles o fazem para riscos que não são tão difundidos antes, no caso do regime de regulação de risco financeiro, ou que podem ser fortemente diminuídos por um conjunto diferente de instituições que visam minimizar a volatilidade em primeiro lugar. Ou seja, os derivativos são redundantes como mecanismo de gestão de riscos. Ainda, no caso dos derivativos, os riscos podem ser agravados pela própria especulação propiciada pelos derivativos. E essa especulação parece ser um dos mais importantes determinantes da financeirização que se seguiu à desregumentação e à liberalização.

\subsection{Volatilidade macrofinanceira e financeirização}

A identificação do regime de regulamentação do período pós-Segunda Guerra com a Idade Dourada do capitalismo, possibilitada pela estabilidade macrofinanceira, levanta dúvidas sobre as razões para a superação daquele regime pelo neoliberalismo, caracterizado por maior 
instabilidade, menor crescimento e piora na distribuição de renda e riqueza. Ellen Russell (2008) explica o fim do que ela chama de "capitalismo de Estado do Bem-Estar keynesiano" como o resultado de uma reação por parte das instituições financeiras contra as normas impostas pelos governos para baratear o crédito e facilitar a expansão industrial e comercial, impondo barreiras para uma rápida expansão de lucros financeiros como proporção da renda nacional. A reação ocorreu por meio de inovações financeiras para evitar a regulamentação e os controles. Segundo a autora, essas mudanças seriam captadas pela dialética regulatória já discutida. Portanto, de acordo com Russell, um conflito distributivo significativo entre diferentes frações do capital poderia estar no centro dessa transição, com instituições financeiras progressivamente introduzindo inovações como uma forma de evitar as regulamentações existentes e auferir lucros maiores. O resultado foi o progressivo desmonte das regulamentações e controles e uma forte expansão dos lucros financeiros, incluindo atividades especulativas que necessitam de volatilidade para se efetivar.

Resta a questão de saber se essa redistribuição crescente de renda e riqueza em favor do setor financeiro provocada pelas inovações financeiras, pela volatilidade elevada e pela desregulamentação e liberalização poderia ser associada a um aumento da eficiência financeira e à consequente melhora no desempenho econômico. A teoria econômica convencional prevê que a privatização em geral, e a da gestão de risco em particular, produz ganhos de bem-estar como resultado da utilização de mecanismos descentralizados de mercado. Frank Knight, por exemplo, postula que:

Mais especificamente, a maioria dos projetos de melhoria social envolvem a substituição de alguma forma, social ou política, mais consciente de controle para a propriedade privada e a liberdade individual de contrato. (Knight, ([1921] 1971, p. IX. Tradução do autor)

Nesse sentido, a explosão no volume e o valor das operações com derivativos envolvendo variáveis financeiras, que excede em muito o crescimento do setor real, poderia sugerir que a exposição ao riscos financeiros ampliados de fato aumentou a um ritmo elevado desde o colapso de Bretton Woods (Steinherr, 2000). Nesta perspectiva, esses instrumentos 
proporcionariam mecanismos de gestão de risco importantes em um contexto de aumento nas flutuações nos preços financeiros após o fim das restrições artificiais impostas pelos governos, agregando valor para os usuários finais (Scholes, 1998; Miller, 1997). Outros autores argumentam que em um contexto de mercados imperfeitos, os riscos financeiros afetam as finanças corporativas e as decisões de investimento, invalidando a proposição de Modigliani-Miller de que a composição das obrigações não é importante, e reforçando o papel dos derivativos na gestão privada dos riscos (Smith et al., 1989; Froot et al., 1994).

Ou seja, as abordagens convencionais enfatizam o desenvolvimento dos derivativos financeiros como a resolução de um problema real, em que a necessidade de proteção seria satisfeita pelos derivativos criados pelas instituições financeiras. No entanto, é necessário perguntar se essa transformação da gestão de risco tem sido eficaz na redução da volatilidade ou em minimizar as suas consequências, contribuindo, por exemplo, para uma expansão das atividades produtivas, como argumentado por Scholes (1998), que poderia estar associada a ganhos inquestionáveis ou "melhoria social", e assim justificar a crescente apropriação de renda e riqueza pelo setor financeiro. Miller (1997) inadvertidamente sugere que os derivativos financeiros, principalmente opções de ações negociadas nas bolsas de Chicago, estariam associados ao declínio dos derivativos nos mercados agrícolas tradicionais e à necessidade de diversificação da carteira no setor financeiro. Assim, o desenvolvimento dos derivativos também pode ser interpretado como um processo refletindo as exigências de maior lucratividade financeiras que caracterizam o processo de financeirização.

Especificamente, os mercados de derivativos de commodities agrícolas estagnados, somados à ampliação da volatilidade macrofinanceira, poderiam ter levado ao processo de diversificação e inovação financeira que culminou com a criação dos derivativos financeiros. Este é essencialmente um processo dirigido pelo lucro financeiro, independentemente da proteção que pudesse existir para alguns usuários finais e no qual a volatilidade é essencial para aumentar os lucros por meio de atividades especulativas, principalmente pela alavancagem proporcionada pelos derivativos. O progressivo desmonte do regime regulatório e a expansão dos instrumentos derivativos para variáveis financeiras não refletiria, assim, um aumento na eficiência no gerenciamento dos 
riscos, mas uma forma nova de se lucrar com estes mesmos riscos. ${ }^{7}$ Não obstante o fato de que inovações são sempre motivadas pela busca de lucro pelas instituições financeiras, como sugerido por Minsky (1982), e que há sempre alguma necessidade a ser atendida, os derivativos financeiros podem ser um produto que reforça este movimento de financeirização. Existiria assim uma tendência à preponderância da especulação, ou o que Keynes (1930) e Davidson (1972) chamam de circulação financeira, sobre as atividades produtivas ou de circulação industrial, ou, em termos marxistas, a predominância do circuito do capital-dinheiro, predominantemente fictício, dada por M - M', sobre a circulação de mercadorias e capital presente no circuito do capital industrial M - C - M' (Marx, 1976). ${ }^{8}$

Mais importante, a evidência empírica apresentada por Orhangazi (2008) e Stockhammer (2004, sugere uma relação negativa entre financeirização, acumulação de capital e crescimento econômico. Portanto, é questionável se a maior liberdade de movimento de fundos financeiros, de livre flutuação dos preços e de expansão dos derivativos representa efetivamente uma melhora na eficiência econômica e na gestão dos riscos macrofinanceiros. Nesse caso, o crescimento dos derivativos poderia refletir apenas a existência de inovações que visam a aumentar a parcela dos lucros financeiros na renda nacional, ou seja, da financeirização. Por outro lado, ao mesmo tempo em que a financeirização reduz a acumulação real, ela amplia a circulação de fundos especulativos na esfera financeira. Por sua vez, a natureza da especulação exige um aumento da flexibilidade na mobilidade de fundos, o que amplia a velocidade de compra e venda. Ou seja, financeirização e especulação exigem ampliação da liquidez. Da mesma forma, risco e incerteza aumentam a preferência pela

\footnotetext{
${ }^{7}$ A existência de empresas empregando derivativos primariamente para se proteger da volalilidade não invalidaria este argumento, desde que o risco fosse transferido para outra parte, ampliado por meio de operações alavancadas e redistribuído para um número maior de carteiras. O valor em risco nesta cadeia secundária de operações pode superar o valor inicialmente protegido. Ou seja, se a tendência envolve mais especulação do que proteção, os derivativos não devem ser entendidos como respondendo ao fim do regime de regulamentação e controles, mas como uma forma de reforçar a volatilidade e criar oportunidades de lucro. ${ }^{8}$ Crotty (2007) mostra que os derivativos são um dos mais importantes determinantes do aumento substancial da rentabilidade dos bancos no período mais recente, mas que esta rentabilidade está dissociada de quaisquer melhorias da eficiência na intermediação financeira.
} 
liquidez como mecanismo de proteção e reduzem a acumulação. Ambas as mudanças atuam em conjunto no sentido de elevar a preferência pela liquidez. A próxima seção discute especificamente os mecanismos pelos quais esse movimento risco-liquidez-especulação opera.

\section{Preferência pela liquidez como um comportamento relacionado ao risco, inclusive macrofinanceiro, e à incerteza}

À medida que o rápido crescimento dos instrumentos derivativos reflete uma mudança na natureza da criação e gestão dos riscos macrofinanceiros em mercados desregulamentados, ele aponta para uma possível modificação nos efeitos que a exposição ao risco tem sobre a composição dos ativos das empresas. Essa expansão também reformula as condições financeiras em que essas decisões de composição são tomadas, estabelecendo novas ligações entre o presente e o futuro. Isso sugere que o crescimento dos derivativos pode ter afetado a decisão das empresas não financeiras em acumular ativos líquidos como um mecanismo de proteção contra os riscos, reduzindo a quantidade de ativos líquidos e permitindo que empresas assumam projetos mais arriscados de investimento. Isso porque, em tese, as empresas com maiores oportunidades de cobertura contra riscos financeiros devem ser capazes, ceteris paribus, de financiar ativos com valor presente líquido positivo (Froot et al., 1993; Smith et al., 1989). Esses investimentos não seriam possíveis sem esse conjunto ampliado de oportunidades, o que reduz a preferência pela liquidez, aumenta a acumulação de capital, o crescimento econômico e, potencialmente, o desenvolvimento no caso das economias em desenvolvimento. ${ }^{9}$

\footnotetext{
${ }^{9}$ Existem vários outros riscos associados às diferentes atividades econômicas que contribuem para aumentar a incerteza, incluindo riscos operacionais derivados de mudanças inesperadas em vendas e estoques, mudanças nos custos do trabalho, riscos de crédito, mudança nos custos das matérias-primas etc., muitos dos quais não podem ser cobertos senão por meio de ativos líquidos. Crotty (2005) discute o impacto negativo do neoliberalismo sobre as empresas não financeiras, sugerindo que a competição acirrada poderia ser considerada uma outra fonte de riscos potenciais para as empresas. Com relação ao risco de crédito, Kalecki (1937) desenvolveu o princípio do risco crescente, quando fundos externos são necessários para financiar projetos de investimento, e Keynes (1964) discutiu a existência de risco de crédito entre devedores e credores. Derivativos de risco de crédito
} 
Embora os riscos macrofinanceiros não sejam necessariamente os únicos determinantes da preferência pela liquidez, ao isolá-los das condições macrofinanceiras mais gerais e enfatizar seus efeitos sobre a composição de ativos das empresas, pode-se avaliar a eficácia dos derivativos financeiros no tratamento da exposição ao risco no processo de financiamento da acumulação de ativos. Dessa forma, os derivativos financeiros podem afetar a composição de ativos de empresas, contribuindo para a acumulação de capital e mitigando a necessidade de retenção de ativos líquidos como um comportamento em relação ao risco. Mas à medida que os derivativos são componentes do processo de financeirização, eles não reduzem a acumulação adicional de ativos líquidos em um mundo de volatilidade ampliada, e permitem maior especulação ao mesmo tempo em que cai o ritmo de acumulação de capital. A relação entre preferência pela liquidez e riscos financeiros pode igualmente ser estendida à regulação dos mercados financeiros. Assim, uma regulamentação eficaz deve ser consistente com níveis reduzidos ou em declínio de preferência pela liquidez, posto que mecanismos adequados de proteção minimizam a necessidade de manter um montante excessivo de ativos líquidos como forma de seguro. Ou seja, os controles administrativos poderiam reduzir os riscos macrofinanceiros e permitir um ambiente mais estável para o planejamento dos compromissos financeiros, aliviando os montantes precaucionários de dinheiro e induzindo mais investimentos.

Isso sugere que a criação e o tratamento dos riscos financeiros podem ter importantes implicações macroeconômicas, o que justifica uma tentativa de fornecer uma melhor compreensão sobre a relação entre os mecanismos para tratar a volatilidade financeira e os padrões de preferência pela liquidez refletidos na composição de ativos. A preferência pela liquidez é especialmente relevante para o problema da canalização de fundos potencialmente disponíveis para a expansão e plena utilização da capacidade produtiva da sociedade, contribuindo para o crescimento (Davidson, 1972). Como a preferência pela liquidez representa uma decisão voluntária de não expandir o capital físico ou a produção e a renda, pode ser uma medida relevante da eficácia dos diferentes mecanismos de gestão de riscos macrofinanceiros.

podem ser empregados para proteger contra estes riscos. Da mesma forma, os derivativos de commodities podem ser utilizados para proteger contra a volatilidade do preço das matérias-primas. Esses instrumentos podem igualmente ser empregados para especulação. 


\subsection{Volatilidade, incerteza e preferência pela liquidez}

Keynes argumenta, na Teoria Geral, que a preferência pela liquidez é um importante indicador do comportamento econômico em relação à incerteza. Com relação especificamente à decisão de manter ativos líquidos, há controvérsias sobre o significado da preferência pela liquidez ou sobre o que constitui um ativo líquido. Alguns autores veem a preferência pela liquidez como um conceito equivalente à procura por moeda, enquanto outros enfatizam a demanda por segurança que encontra em ativos líquidos em geral, e no dinheiro em particular, uma forma de seguro ou proteção. Chang (1983), por exemplo, definem a preferência pela liquidez como uma demanda por títulos de curto prazo sobre outros valores mobiliários em uma carteira. Lippman e McCall (1986) utilizam um modelo neoclássico de procura por emprego para definir a liquidez como uma característica de qualquer ativo vendido sob uma política de venda ótima, que minimiza o tempo necessário para transformar o ativo em dinheiro. Keynes (1964) considera a preferência pela liquidez em termos da composição de carteira ou riqueza entre ativos líquidos e ilíquidos, empregando uma definição elástica de dinheiro, que engloba títulos de diferentes maturações. Da mesma forma, Tobin (1958), com o objetivo de fornecer microfundamentos neoclássicos para a preferência pela liquidez como um comportamento em relação ao risco, mede-a como a proporção de moeda sobre a proporção de obrigações perpétuas em uma carteira constituída exclusivamente de ativos financeiros.

Mais importante no que diz respeito à relação entre preferência pela liquidez e volatilidade financeira, Keynes enfatiza a correlação entre a incerteza sobre as taxas futuras de juros e a preferência pela liquidez "[...] a incerteza quanto à evolução futura da taxa de juros é a única explicação inteligível do tipo de preferência pela liquidez L2, que leva à retenção de dinheiro M2" (1964, p. 201, itálico no original, tradução do autor). Minsky (1979) especifica, com base em sua análise das diferentes estruturas de endividamento e compromissos financeiros, como as posições especulativas e do tipo Ponzi são mais suscetíveis de serem afetadas pela possibilidade de reversão do valor presente, tornando-o negativo quando as taxas de juros sobem. Para as unidades mantendo essas posições, moeda e títulos do mercado monetário são empregados como um seguro contra falhas de refinanciamento quando as taxas de juros são voláteis. 
Em outro trabalho, Minsky (1975) chama a atenção para o uso do dinheiro como uma apólice de seguro contra a incerteza, como uma proteção contra quaisquer contingências adversas, não apenas volatilidade financeira. Stephen Rousseas (1986) adota uma visão semelhante, enfatizando o uso do dinheiro como um mecanismo de proteção contra a incerteza e, portanto, não neutro em uma economia monetária da produção.

Axel Leijonhufvud (1968) discute como o risco de taxa de juros, e não a incerteza, afeta a composição das carteiras. Ele afirma que, para Keynes, a distinção entre bens de capital e ativos financeiros é menos importante do que as mudanças na taxa de juros para compreender as decisões sobre a aquisição de diferentes tipos de ativos. Destaca, também, as penalidades ou custos associados a níveis insuficientes de liquidez para tratar a incerteza sobre o fluxo de caixa, bem como os custos de oportunidade de proteção utilizando saldos de caixa em excesso. ${ }^{10}$ Paul Davidson (1992) argumenta que a manutenção de uma quantidade adequada de ativos líquidos é a única forma conhecida de proteção contra a incerteza que possa levar à insolvência.

Algumas ressalvas são necessárias neste estágio. Em primeiro lugar, flutuações nas taxas de câmbio, e não apenas volatilidade da taxa de juros, podem igualmente ser uma importante fonte de instabilidade, principalmente no contexto dos mercados mundiais integrados de bens, moeda e capital. Contudo, o impacto das flutuações nas taxas de câmbio sobre a preferência pela liquidez é possivelmente menor, uma vez que esse tipo de volatilidade tem menor capacidade de produzir as reversões de "valor presente" enfatizadas por Minsky, em seu tratamento das alterações da taxa de juro para o investimento em ativos reais. Isso também pode explicar o menor volume relativo de contratos negociados em moeda estrangeira nos mercados de derivativos, principalmente os instrumentos negociados em bolsas de valores, e a predominância relativa dos contratos de taxa de juros. No entanto, como taxas de câmbio e taxas de juros estão relacionadas, e os fluxos financeiros entre países são importantes na composição de ativos, a volatilidade cambial é um fator importante.

\footnotetext{
${ }^{10}$ Smith et al. (1989) discutem a necessidade de cobertura de riscos com o uso de derivativos em termos do que Leijonhufvud chama de penalidade: a possibilidade de crise financeira e insolvência.
} 
Em segundo lugar, vale ressaltar que risco e incerteza não são a mesma coisa. A distinção não é trivial, e Marshall Auerback (2007) atribui a crise financeira de 2007 à incapacidade das instituições financeiras em entender a diferença. Em contraste com Tobin e Leijonhufvud, que raciocinam em termos de risco, os autores pós-keynesianos ressaltam o papel da incerteza fundamental na tomada de decisão (Chick, 1983; Davidson, 1972). Incerteza fundamental implica uma situação em que se reconhece que o futuro é inerentemente incognoscível e não mensurável, ao contrário do risco, situação em que as distribuições de probabilidade com base em frequências conhecidas são atribuídas a eventos futuros. Nesta segunda perspectiva, o futuro pode ser estimado ou, pelo menos, de forma imperfeita, mensurável por meio de distribuições de probabilidade. Essas distribuições são baseadas em frequências históricas e no pressuposto de que a economia pode ser caracterizada por processos ergódicos em que as médias futuras não podem desviar por uma margem grande das médias passadas, justificando o uso de dados históricos para projetar tendências futuras. Por outro lado, em condições caracterizadas pela incerteza fundamental, o passado não é um instrumento útil para prever o futuro. A história é um processo de mudança contínua, e o cálculo de probabilidades com base na frequência pode ser irrelevante, resultando em um estado de completa ignorância sobre o futuro, quando as decisões cruciais e singulares sobre a acumulação de capital estão envolvidas. Essa situação, contudo, não implica instabilidade contínua. Crotty (1994), por exemplo, argumenta como as instituições e os contratos podem conferir estabilidade condicional para a economia, não obstante a existência de incerteza fundamental.

Ou seja, é possível argumentar que a preferência pela liquidez também pode ser considerada um comportamento em relação aos riscos, incluindo riscos financeiros, e não apenas em relação à incerteza fundamental. A atribuição de distribuições de probabilidades baseadas em dados históricos a eventos futuros poderia ser considerada uma convenção amplamente adotada pelos agentes, no sentido discutido por Keynes em seu artigo no QJE, em 1937. Essa convenção poderia reduzir à incerteza como percebida subjetivamente pelos participantes, mesmo que essa prática não possa eliminá-la objetivamente e esteja sujeita a mudanças repentinas. Isto é, as tentativas de domesticar a incerteza por meio de atribuição de distribuições de probabilidade, à medida que se 
trata de uma convenção social seguida por muitos agentes, pode também reforçar o grau de confiança sobre a distribuição de probabilidade estimada, independentemente de quão inexatos estes cálculos podem vir a ser a posteriori. ${ }^{11}$

Feitas as ressalvas, os impactos dos distintos mecanismos de tratamento dos riscos macrofinanceiros sobre a preferência pela liquidez podem ser resumidas e ilustradas por meio de um exemplo gráfico.

\subsection{Uma exposição gráfica}

À medida que os riscos macrofinanceiros elevados aumentam a incerteza sobre os resultados futuros, diferentes mecanismos desenvolvidos para tratar desta volatilidade excessiva podem afetar a preferência pela liquidez como um comportamento diretamente em relação ao risco e indiretamente em relação à incerteza, desde que sejam eficazes. Ou seja, é possível argumentar que existe uma relação entre a incerteza fundamental, os riscos macrofinanceiros, os mecanismos que regulam a criação e a gestão desses riscos, bem como a composição de ativos das empresas. Jan Toporowski (1998 e 2001) discute como os derivativos podem afetar a liquidez na composição de ativos, considerada uma forma natural de proteção em uma economia existente no tempo histórico. Toporowski (2001) sugere explicitamente uma conexão entre a preferência pela liquidez, incerteza e riscos para as empresas não financeiras

\footnotetext{
${ }^{11}$ E pode ainda existir uma relação entre os riscos calculados e a incerteza percebida subjetivamente, à medida que se torna mais difícil projetar o futuro em circunstâncias de maior volatilidade nos preços macrofinanceiros. Nesse sentido, é possível argumentar que a incerteza sobre as taxas de câmbio sob Bretton Woods, com volatilidade reduzida, foi menor do que a incerteza sobre estas taxas sob um regime de câmbio flutuante com o aumento da volatilidade. Mais importante para os nossos propósitos, se se pode mostrar que a preferência pela liquidez está associada a alguma medida operacional de riscos financeiros, à medida que o aumento da volatilidade torna menos confiáveis as projeções financeiras e estimativas de fluxo de caixa, pode-se argumentar que essa relação reforça a hipótese pós-keynesiana. Isso porque a convenção de atribuir distribuições de probabilidade «conhecidas de forma assumida» a eventos futuros «conhecidos de forma assumida» pode não eliminar a necessidade de retenção de ativos líquidos por completo, nem mesmo com derivativos, como se mostra a seguir.
} 
A razão pela qual apenas um pequeno número de grandes empresas utilizam os mercados financeiros futuros para evitar riscos é porque tais instrumentos são inferiores à preferência pela liquidez, muito mais comumente utilizada como forma de evitar riscos (Toporowski, 2001, p. 108. Tradução do autor).

A visão neoclássica dos mercados financeiros futuros é que eles são um recurso que projeta determinados valores para um futuro incerto, ou pelo menos substitui valores incertos por um "valor de certeza-equivalente", que refletem "riscos" futuros. Se este fosse o caso, então, em igualdade de condições, seria de se esperar uma redução na preferência pela liquidez devido à incerteza na medida em que a utilização de mercados financeiros futuros tem proliferado desde os anos 1970 (Toporowski, 2001, p. 103. Tradução do autor).

Toporowski sugere, assim, que os derivativos financeiros e a preferência pela liquidez poderiam ser substitutos e que, como os derivativos não compensam os riscos de uma forma eficaz, as empresas recorrem aos ativos líquidos para se proteger. A fim de ilustrar como diferentes arranjos podem afetar os riscos financeiros e a preferência pela liquidez, um exemplo gráfico é proposto a seguir. Assume-se que, da perspectiva das empresas não financeiras, um dado nível de risco macrofinanceiro é determinado exogenamente pelo nível de regulação presente no sistema financeiro. ${ }^{12}$ Isso significa que os riscos são criados de acordo com uma medida dos graus de liberdade dos mercados financeiros na determinação dos preços e fluxos financeiros, isto é, tanto pela existência e aplicação de regulamentações e controles como pela existência de atividades especulativas potencialmente desestabilizadoras nos mercados financeiros (Figura 1 a seguir). Supõe-se que a regulação financeira eficaz tende a reduzir os riscos macrofinanceiros, criando res-

\footnotetext{
${ }^{12}$ Uma matéria no The Wall Street Journal destaca este ponto (Timiraos, 2008, grifo e tradução do autor). De acordo com a reportagem, “... a regulamentação tem suas limitações, diz Alex J. Pollock, membro residente no conservador American Enterprise Institute. "Não importa o que qualquer regulador ou legislador faça, os mercados financeiros criarão tanto risco quanto eles quiserem.” No entanto, parece que os reguladores de Bretton Woods, e os legisladores do Regulamento Q e Glass-Steagall nos EUA de fato conseguiram conter a capacidade dos mercados financeiros na criação de mais riscos.
} 
trições sobre a capacidade das instituições financeiras em aumentar ou diminuir a frequência das transações com ativos e passivos financeiros. Além disso, a desregulamentação financeira e a liberalização tendem a criar mais espaço para a atividade no mercado financeiro, incluindo o potencial para posições especulativas desestabilizadoras, e do consequente aumento na volatilidade. Supõe-se também que a preferência pela liquidez é medida pela proporção de ativos líquidos sobre o ativo total e é uma função linear de riscos macrofinanceiros. Essa medida de preferência pela liquidez assume que a demanda transacional por moeda e os ativos aumentam proporcionalmente com a renda. Finalmente, admite-se inicialmente que a preferência pela liquidez das empresas não financeiras não afeta os riscos macrofinanceiros. ${ }^{13}$

Assim, um determinado nível de regulação financeira determina os riscos macrofinanceiros, medida por um índice $\sigma_{\mathrm{M} 0}$ contendo uma dada medida da volatidade das taxas de câmbio e de juros, e o nível correspondente de preferência pela liquidez $\mathrm{L}_{0}$. Com reduzidos níveis de volatilidade macrofinanceira, as empresas podem manter, ceteris paribus, uma fração menor de ativos líquidos como um mecanismo de proteção, com a ocorrência inversa para níveis elevados de riscos macrofinanceiros. ${ }^{14}$ Nesse caso, é preciso supor adicionalmente a existência de um nível mínimo absoluto de preferência pela liquidez, Lm, já que as empresas sempre precisam de uma certa quantidade mínima de liquidez em seus balanços para realizar transações regulares, como sugerem o motivo transações e o motivo financeiro propostos por Keynes. Este mínimo deve ser variável para as diferentes fases do ciclo econômico e das diferentes fases de desenvolvimento capitalista, refletindo os impactos das inovações financeiras e da existência de diferentes percepções de risco. O "excesso" de preferência pela liquidez acima do mínimo fornece uma indicação do valor potencial dos recursos "desviados" da acumulação real.

\footnotetext{
${ }^{13}$ Poder-se-ia igualmente argumentar, seguindo Minsky, que, se as empresas estão excessivamente confiantes e mantêm ativos relativamente menos líquidos, isso pode levar a um aumento da fragilidade financeira e do potencial de instabilidade financeira. Se a instabilidade aumenta os riscos macrofinanceiros, então a linha de regulação financeira para a economia como um todo teria que ser inclinada para baixo, apresentando uma causalidade inversa em que a liquidez insuficiente leva à fragilidade financeira, a fragilidade financeira leva à instabilidade financeira e instabilidade financeira leva a uma maior volatilidade financeira.

${ }^{14}$ A suposição de ceteris paribus é importante, dado que alterações em outras variáveis, tais como as expectativas e os riscos não financeiros, incluindo mudanças nas variáveis reais, poderiam igualmente modificar a forma da função de preferência de liquidez.
} 
Como os riscos e a incerteza são características intrínsecas do capitalismo e mercados descentralizados, $\sigma_{\mathrm{M} 0}$ é sempre positivo, e não parece incorreto presumir que a preferência pela liquidez refletida na demanda precaucional de moeda $\mathrm{L}_{0}$ também é sempre positiva. Da mesma forma, há que se ressaltar que há um limite teórico para a fração máxima de ativos líquidos que uma determinada empresa pode manter, igual à unidade, mas este limite dificilmente seria alcançado no mundo real, mesmo para as instituições financeiras. Alguns ativos são ilíquidos por necessidade, e esta falta de liquidez tende a ser uma fonte de incerteza para os capitalistas engajados em atividades de investimentos físicos no mundo real, como sugerido por Keynes e Davidson.

A Figura 2 a seguir mostra como os dois mecanismos para tratar do risco macrofinanceiro podem afetar a preferência pela liquidez das empresas. A regulação financeira eficaz desloca a linha de regulação financeira para a esquerda e reduz a volatilidade macroeconômica para $\sigma_{\mathrm{G}}$, com o nível inicial (anterior à regulação eficaz) $\sigma_{\mathrm{M} 0}>\sigma_{\mathrm{G}}$. Isso implica, ceteris paribus, uma diminuição na preferência pela liquidez dos níveis iniciais $\mathrm{L}_{0}$ para um novo nível, menor, $\mathrm{L}_{1}$, liberando fundos para a acumulação de ativos reais. Por outro lado, a desregulamentação e a liberalização financeira dariam mais liberdade para os mercados e para as instituições financeiras, deslocando a linha de regulamentação para a direita e levando a uma maior volatilidade $\sigma_{\mathrm{M1}}$, maior do que o nível inicial antes da desregulamentação, isto é, $\sigma_{\mathrm{M} 0}<\sigma_{\mathrm{M} 1}$. Isso pode causar uma elevação na proporção de ativos líquidos, dos níveis iniciais $\mathrm{L}_{0}$ para níveis superiores $\mathrm{L}_{2}$, ceteris paribus. Por outro lado, os derivativos poderiam oferecer mecanismos para compensar os níveis elevados de riscos financeiros ao nível da empresa, mas sem alterá-los no agregado, já que os derivativos simplesmente redistribuem riscos. Caso sejam eficazes no fornecimento de mecanismos de proteção, esses instrumentos reduzem os níveis individuais de risco financeiro e são consistentes com níveis mais baixos de preferência pela liquidez, que diminui dos níveis iniciais $\mathrm{L}_{0}$ para $\mathrm{L}_{3}$ (ou qualquer outro nível entre $\mathrm{L}_{2}$ $\mathrm{e}_{\mathrm{m}}$ ). Istrumentos financeiros derivativos eficazes, portanto, poderiam mudar a inclinação da função de preferência pela liquidez, tornando as empresas menos sensíveis aos níveis agregados de riscos existentes. No caso extremo em que os derivativos financeiros são perfeitamente eficazes, eles podem fazer com que a função de preferência pela liquidez se torne horizontal, tornando a preferência pela liquidez insensível a riscos macrofinanceiros e reduzindo-a de $\mathrm{L}_{2}$ para o nível mínimo $\mathrm{L}_{\mathrm{m}}$. 


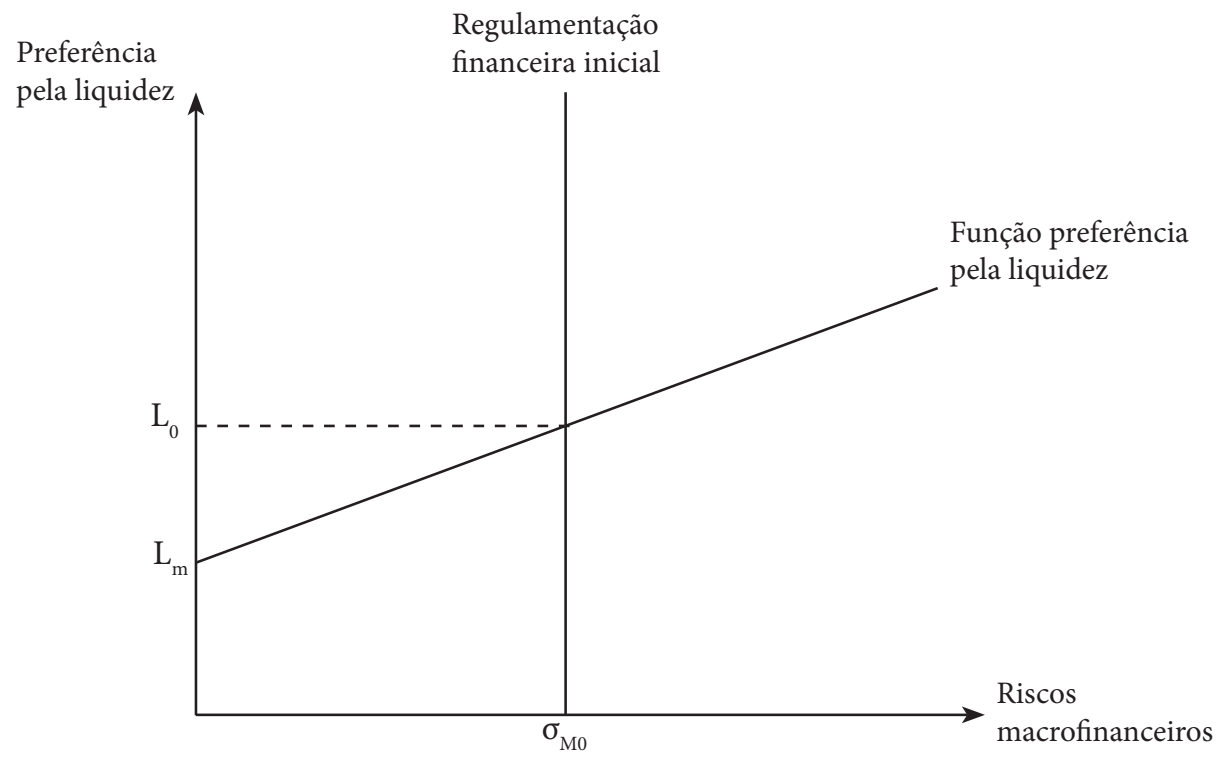

Figura 1. Regulamentação financeira, riscos macrofinanceiros e preferência pela liquidez de uma empresa não financeira

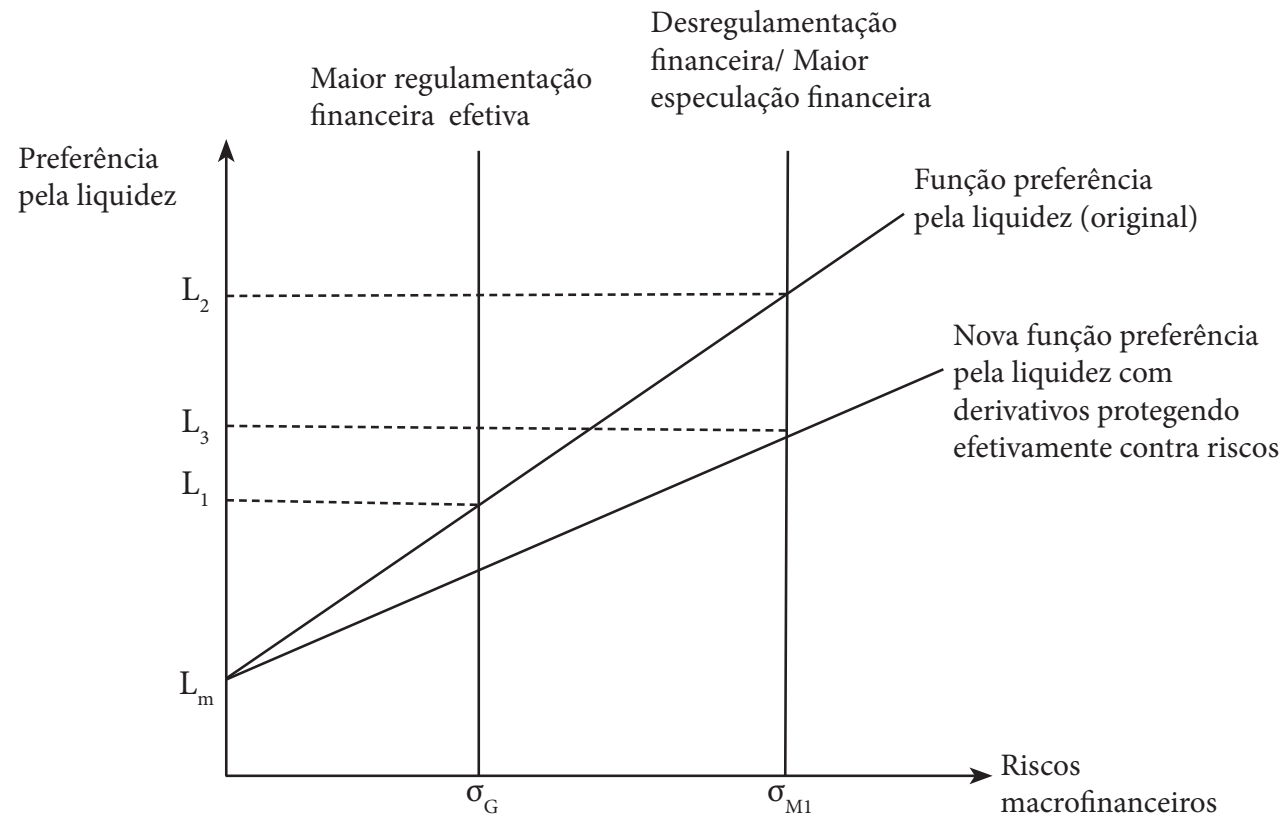

Figura 2. Efeitos de mudanças na regulação financeira e dos derivativos financeiros sobre riscos financeiros e preferência pela liquidez 
Por outro lado, à medida que os derivativos financeiros aumentam a volatilidade por meio de intensificação da atividade especulativa, e assumindo que a especulação é em média desestabilizadora, a linha de regulação financeira poderia ser deslocada ainda mais para a direita. Isso aumentaria a retenção de ativos líquidos e, talvez, pudesse mesmo compensar parcial ou totalmente a redução inicial da preferência pela liquidez provocada pela proteção, como refletido na redução da sensibilidade aos riscos. Da mesma forma, a existência de mecanismos alternativos ao ativo de "proteção» padrão, tais como contratos de longo prazo, subsidiárias estrangeiras, dívidas com taxas fixas de juros, poderiam mudar a inclinação da função de preferência pela liquidez, ou até mesmo os níveis mínimos de liquidez Lm.

Como anteriormente discutido, a liquidez pode também estar correlacionada com a tomada de riscos financeiros, ou especulação, em vez de compensá-los. A acumulação de ativos líquidos motivada pela segurança muitas vezes não pode ser adequadamente distinguida da preferência pela liquidez motivada por retornos financeiros. Por exemplo, Robert Pollin e Marc Schaberg (1998) sugerem a existência de uma relação entre transações no mercado financeiro e retenção de ativos líquidos. John Marthinsen (2005) também aponta a recente transformação dos departamentos de tesouraria em centros de lucro e a tendência crescente de utilização da liquidez para especular com ativos financeiros ao invés da cobertura de fluxos de caixa e proteção das margens operacionais médias. Marthinsen, fazendo eco a Minsky, argumenta que a motivação pelo lucro está sempre presente na decisão de assumir mais riscos e de se afastar da segurança. Da mesma forma, Dale Gray (2007) argumentam que a volatilidade nos valores dos ativos podem ser correlacionados com posições financeiras frágeis e propícias a riscos de crédito, dando apoio, obviamente não reconhecido, à hipótese da instabilidade financeira de Minsky. Eles argumentam ainda que os ativos líquidos podem servir como um amortecedor para estas flutuações no preço de ativos menos líquidos. De qualquer forma, quer para compensar a insuficiência dos derivativos na proteção contra os riscos, quer para aumentar a flexibilidade e facilitar a especulação financeira, o aumento da acumulação de ativos líquidos contribui para reduzir a acumulação de ativos reais, o crescimento e desenvolvimento econômico potencial. 


\section{Conclusão}

A discussão precedente sobre os diferentes mecanismos desenvolvidos para gerir os riscos macrofinanceiros do capitalismo e os correspondentes impactos sobre a acumulação de ativos sugere que a desregulamentação, a liberalização e os derivativos financeiros que são criados no processo não são necessariamente os mecanismos mais eficazes para estabilizar preços e fluxos financeiros. Sugere ainda que, à medida que a volatilidade tem impactos consideráveis sobre as condições macroeconômicas de financiamento da acumulação de capital, já que as taxas de juros e de câmbio representam uma importante fonte de exposição para as empresas e, portanto, sobre as condições de crescimento e desenvolvimento sob condições capitalistas, o seu tratamento não pode ser deixado exclusivamente aos impulsos especulativos das instituições financeiras.

Enquanto durou, o regime de controle dos riscos macrofinanceiros foi relativamente eficaz e coerente em impedir que os mercados e instituições financeiras pudessem determinar de modo exclusivo os preços e os fluxos financeiros mais relevantes e, assim, exacerbar a volatilidade financeira. Esse regime preveniu a criação dos riscos macrofinanceiros, em vez de redistribuí-los depois de criados, e o nível de risco que se seguiu foi efetivamente menor, afetando de forma positiva todas as atividades com alguma exposição, ao mesmo tempo em que diminuiu o escopo da atividade especulativa que se alimenta da volatilidade. Assim, o regime era potencialmente consistente, ou pelo menos não potencialmente conflitante, como supõe a ortodoxia, com a rápida expansão da produção do emprego e da renda, como o registro histórico do capitalismo regulado sugere. Sem dúvida, a regulamentação financeira cria endogenamente uma reação na forma de inovações introduzidas para evitar os controles, minando dialeticamente os próprios fundamentos da regulamentação. Isso apenas sugere, no entando, que nenhuma estrutura institucional pode ser considerada evolucionariamente estável sob o capitalismo.

Já a expansão dos derivativos não parece ter conseguido evitar os efeitos da volatilidade financeira sobre a acumulação de capital ou mesmo sobre a estabilidade macrofinanceira. Os derivativos financeiros ainda poderiam ser considerados complementos, e não substitutos como sugerido por Toporowski, à preferência pela liquidez. Aqui seria preciso mostrar que os mercados financeiros desregulamentados tendem a re- 
solver completamente as consequências adversas associadas à falta de coerência global dos derivativos financeiros, uma vez que os riscos financeiros não são reduzidos, apenas redistribuídos sob tal abordagem. Neste caso, haveria uma redistribuição da liquidez global para complementar o uso de derivativos. A recente crise financeira, porém, sugere que os derivativos financeiros não forneceram amortecedores, isto é, os necessários instrumentos eficazes e coerentes de gestão de risco contra a volatilidade e a instabilidade financeira. O rápido crescimento dos derivativos financeiros pode, então, ser entendido não como um valor adicionado pelos mercados financeiros, mas em grande medida como reflexo da necessidade de diversificação das carteiras das instituições financeiras no contexto da desregulamentação dos mercados financeiros, que surgiu como uma consequência das inovações introduzidas por essas instituições. Em outras palavras, os derivativos financeiros, refletindo as mudanças macrofinanceiras e a mudança de orientação da política financeira, culminaram na financeirização do capitalismo, acrescentando relativamente mais fundos para a circulação financeira.

Se os mercados financeiros desregulados e liberalizados não conseguem gerar mecanismos mais eficazes para tratar do aumento da volatilidade financeira e das suas consequências, nem propiciar um ambiente macrofinanceiro propício à estabilidade e à expansão produtiva de forma consistentemente superior àqueles alcançados no âmbito da regulamentação, isto sugere um erro fundamental na filosofia econômica que informa a privatização dos controles dos riscos macrofinanceiros, como duramente aprendida por Alan Greenspan, durante a recente crise financeira.

Finalmente, considerada em termos da promoção da estabilidade financeira e da mitigação das conseqüências macroeconômicas, fica claro que, em uma economia capitalista intrinsecamente instável, a regulamentação e outras medidas administrativas do Estado que reduzem os graus de liberdade da atividade especulativa, podem desempenhar um papel importante, ainda que recomendações políticas sobre formas específicas de regulação não estejam dentro do escopo deste capítulo. ${ }^{15}$

\footnotetext{
${ }^{15}$ As propostas mais destacadas na literatura incluem uma nova arquitetura financeira internacional nos moldes de Bretton Woods, regulamentação prudencial, o acordo de Basileia III, a taxa Tobin, exigências de reservas lastreadas em ativos para os bancos e a imposição de controles quantitativos sobre os fluxos de capitais de curto prazo.
} 
E essa importância adquire um significado ainda maior quando se considera que os elevados riscos macrofinanceiros podem se tornar um entrave à acumulação de capital, ao alavancar a acumulação excessiva de ativos líquidos e que a alternativa privada ofertada pelos mercados financeiros é ineficaz e inadequada justamente por não permitir a transformação da liquidez em excesso em ativos reais, mas em acumulação financeira de caráter especulativo. Este capítulo sugere, e a crise financeira iniciada em 200, e ainda não resolvida demonstra, que a regulamentação financeira é necessária e desejável nos marcos do capitalismo. É necessária também porque permite modificar a distribuição de renda e riqueza no sentido da produção e do emprego, própria de qualquer reforma financeira eficaz, ainda que conduza inevitavelmente à "dialética regulatória”. Um capitalismo mais estável, ainda que temporariamente, e menos financeirizado, que aumente a produção e a renda em relação à especulação e à volatilidade, e democratize, ainda que parcialmente, os ganhos correspondentes, parece exigir fundamentalmente controles políticos mais rigorosos sobre os preços e fluxos macrofinanceiros e uma redução do papel desempenhado pelas instituições financeiras.

\section{Referências}

ANDREWS, E. Greenspan Concedes Errors on Regulation. The New York Times, B1, 23 de out. 2008.

AUERBACK, M. Risk vs. Uncertainty: The Cause of the Current Financial Crisis. Japan Policy Research Institute, Occasional Paper n. 37, 2007.

BANK FOR INTERNATIONAL SETTLEMENTS (BIS). OTC Market Activity in the Second Half of 2009. Monetary and Economic Department, may 2010.

BANKS, E. Volatility and Credit Risk in the Capital Markets: assessing and managing financial instrument risk and off-balance sheet operations. Probus Publishing Company, 1993.

. Complex Derivatives: understanding and managing the risks of exotic options, complex swaps, warrants and other synthetic derivatives. Probus Publishing Company, 1994.

BERNSTEIN, P. Against the Gods: the remarkable story of risk. New York: John Wiley and Sons, 1998.

BORDO, M. The Bretton Woods International Monetary System: A Historical Overview. In: BORDO, M.; EICHENGREEN, B. (Editors) A Retrospective on the Bretton Woods System: lessons for International Monetary Reform. Chicago: The University of Chicago Press, 1993. 
CARGILL, T. F. US Financial Policy in the Post-Bretton Woods Period. In: DOWD, Kevin; TIMBERLAKE, Richard (Editors) Money and the National State. The Financial Revolution, Government and the World Monetary System. Transaction Publishers, 1997.

CHANG, W.; HAMBERG, D.; HIRATA, J. Liquidity Preference as Behavior Toward Risk is a Demand for Short-Term Securities - Not Money. American Economic Review, v. 73, n.3, p. 420-427, jun. 1983.

CHICK, V. Macroeconomics after Keynes. Cambridge: MIT Press, 1983.

CROTTY, J. Are Keynesian Uncertainty and Macrotheory Compatible? Conventional Decision Making, Institutional Structures, and Conditional Stability in Keynesian Macromodels. In: DYMSKI, G.; POLLIN, R. (Editors) New Perspectives in Monetary Macroeconomics: Explorations in the Tradition of Hyman P. Minsky. Ann Arbor: University of Michigan Press, 1994.

CROTTY, J. The Neoliberal Paradox: The Impact of Destructive Product Market Competition and 'Modern' Financial Markets on Nonfinancial Corporate Performance in the Neoliberal Era. In: EPSTEIN, G. (Editor). Financialization and the World Economy. Cheltenham: Edward Elgar Publishing, 2005.

If Financial Market Competition is so Intense, Why are Financial Firm Profits so High? Reflections on the Current 'Golden Age' of Finance. Political Economy Research Institute, Working Paper n.174, 2007.

DAVIDSON, P. Money and the Real World. New York: Halsted Press, 1972. Press, 1992.

International Money and the Real World. 2. ed. revised. London: Macmillan

EATWELL, J.; TAYLOR, L. Global Finance at Risk: the case for international regulation. New York: The New Press, 2000.

EPSTEIN, Gerald (Ed.) Financialization and the World Economy. Cheltenham: Edward Elgar Publishing, 2005.

FROOT, K.; SCHARFSTEIN, D.; STEIN, J. Risk Management: Coordinating Corporate Investment and Financing Policies. Journal of Finance, 48, p. 1629-1658, dec. 1993.

FROOT, K.; SCHARFSTEIN, D.; STEIN, J. A Framework for Risk Management. Harvard Business Review, nov.-dec. 1994.

GRAY, D.; MERTON, R.; BODIE, Z. New Framework for Measuring and Managing Macrofinancial Risk and Financial Stablity. NBER Working Paper n. 13607, 2007.

HELLEINER, E. States and the Reemergence of Global Finance - From Bretton Woods to the 1990s. Cornell University Press, 1994.

HUBBARD, R. G. Money, the Financial System, and the Economy. 3 ed. Addison-Wesley Longman, 1999.

HULL, J. Introduction to Futures and Options Markets. Englewood Cliffs, Prentice Hall, 1995.

IP, G. His Legacy Tarnished, Greenspan Goes on the Defensive. The Wall Street Journal, apr, 8, 2008.

KALECKI, M. The Principle of Increasing Risk. Economica, v. 3, 1937. 
KEYNES, J. M. A Treatise on Money. Harcourt, Brace and Company, 1930.

. The General Theory of Employment, Interest, and Money. New York: Harvest/ Harcourt Brace Jovanovich, 1964.

KNIGHT, F. H. (1921) Risk, Uncertainty and Profit. Chicago: [reprinted by] University of Chicago Press, 1971.

KRIPPNER, G. The Financialization of the American Economy. Socio-Economic Review, v. 3, 2005.

LEIJONHUFVUD, A. On Keynesian Economics and the Economics of Keynes. New York: Oxford University Press, 1968.

LIPPMAN, S.; McCALL, J. “An Operational Measure of Liquidity”. American Economic Review, v. 76, n. 1, p. 43-55, mar.1986.

LiPUMA, E.; LEE, B. Derivatives and the Globalization of Risk. Durham: Duke University Press, 2004.

MARSTON, R. Interest Differentials under Bretton Woods and the Post-Bretton Woods Float: The Effects of Capital Controls and Exchange Risk. In: BORDO, M.; EICHENGREEN, B. (Editors). A Retrospective on the Bretton Woods System - Lessons For International Monetary Reform. Chicago: The University of Chicago Press, 1993.

MARTHINSEN, Jo. Risk Takers: Uses and Abuses of Financial Derivatives. Boston: Addison Wesley, 2004.

MARX, K. (1867). Capital. A critique of Political Economy, Volume One. UK: Penguin Books Ltd/New Left Review, 1976.

MILLER, M. Merton Miller on Derivatives. New York: John Wiley and Sons, 1997.

MINSKY, H.P John Maynard Keynes. New York: Columbia University Press, 1975.

. The Financial Instability Hypothesis: Capitalist Processes and the Behavior of the Economy. In: KINDLEBERGER, Charles P.; LAFFARGUE, Jean-Pierre (Editors). Financial Crises - Theory, History \& Policy. Cambridge: Cambridge University Press, 1979.

Sharpe, 1982.

. Can "It" Happen Again? Essays on Instability and Finance. Armonk, NY: ME

MINSKY, H.P. Stabilizing an Unstable Economy. New Haven: Yale University Press, 1986.

MOLLENKAMP, C.; NG, S. Wall Street Wizardry Amplified Credit Crisis. The Wall Street Journal, dec. 27, 2007.

NEELY, C. An Introduction to Capital Controls. Review, Federal Reserve Bank of Saint-Louis, nov,-dec., 1999.

NG, S.; LUCCHETTI, A. Street Seeks Credit-Default Safety Net. The Wall Street Journal, april 24, 2008.

ORHANGAZI, Ozgur Financialization and the US Economy. Cheltenham: Edward Elgar Publishing, 2008.

POLLIN, R; SCHABERG, M. Asset Exchanges, Financial Market Trading, and the M1 Income Velocity Puzzle. Journal of Post Keynesian Economics, v. 21 n. 1, Autumn: 135-162, 1998. 
RAFFERTY, M.; BRYAN, D. Capitalism With Derivatives: A Political Economy of Financial Derivatives, Capital and Class. London: Palgrave Macmillan, 2006.

ROUSSEAS, S Post Keynesian Monetary Economics. $1^{\text {st }}$ ed., Armonk, NY: ME Sharpe, 1986.

RUSSELL, E.D. New Deal Banking Reforms and Keynesian Welfare State Capitalism. Routledge, 2008.

SCHOLES, M. Derivatives in a Dynamic Environment. American Economic Review, v. 88, n. 03, jun. 1998 .

SMITH Jr., C. W.; SMITHSON, C. W.; WILFORD, D. S. Managing Financial Risk. New York: Harper and Row, 1989.

STOCKHAMMER, E. Financialization and the Slowdown of Accumulation. Cambridge Journal of Economics, n.28, 2004.

STEINHERR, A. Derivatives - The Wild Beast of Finance. A Path to Effective Globalization?, John Wiley and Sons, 2000.

SWAN, E. Building the Global Market: A 4000 Year History of Derivatives. London: Kluwer Law International, 2000.

TIMIRAOS, N.. Why Banks' Pain Could Continue. The Wall Street Journal, p. 19-20: A11, jan. 2008

TOBIN, J.Liquidity Preference as a Behavior Toward Risk. Review of Economic Studies, v. 25, n. 2, p.65-86, feb. 1958.

TOPOROWSKI, J. The End of Finance: The Theory of Capital Market Inflation, Financial Derivatives and Pension Fund Capitalism. London: Routledge, 1998.

. Financial Derivatives, Liquidity Preference, Competition and Financial Inflation. In: ARESTIS, Philip; SAWYER, Malcolm (Editors) Money, Finance, and Capitalist Development. Cheltenham: Edward Elgar Publishing, 2001.

WOJNILOWER, A. The Central Role of Credit Crunches in Recent Financial History. Brookings Papers on Economic Activity, n.2, 1980. 